\title{
Porous aggregate development for lightweight concrete
}

\author{
Olga Miryuk ${ }^{1, *}$ \\ ${ }^{1}$ Rudny Industrial Institute, Kazakhstan
}

\begin{abstract}
The article presents the results of studies of a porous aggregate and lightweight concrete obtained using liquid glass and man-made materials (glass cullet, magnetite ore dressing waste, substandard rocks). Feasibility of a multicomponent feed mixture for pyroplastic swelling of granules is substantiated. Optimization of raw mix composition provided the possibility of combining various formation mechanisms of porous granules. A set of technological solutions has been developed aimed at improving the conditions of molding and hardening of raw granules. A method for preparing a raw material mass is proposed that minimizes structural defects of porous granules. Possibility of capacity reaction of a raw mixture due to mechanical activation of solid components and introduction of sodium additives is proved. Technological conditions for low-temperature expansion of a multicomponent mixture and production of porous granules with a density of not more than $300 \mathrm{~kg} / \mathrm{m}^{3}$ are determined. The formula of molding mixture for obtaining lightweight concrete using a porous aggregate is proposed. The use of liquid glass as a binder in a concrete mixture is preferred. The temperature of concrete hardening is recommended. The technology of porous concrete developed implements multifunctional properties of liquid glass, provides the use of technogenic materials, saving of energy resources.
\end{abstract}

\section{Introduction}

To ensure energy-efficient construction, durable materials are required that combine high heat-shielding properties with structural stability. Numerous developments in recent years have been devoted to the development of porous concrete technology, which is represented by cellular concrete and lightweight concrete based on porous aggregates [1-17]. Aerated concrete compares favorably with an extensive raw material base, a variety of products, and economical operation. However, low strength and tendency to shrinkage deformations limit the scope of cellular concrete $[4,7,11]$. Development of efficient lightweight concrete technology depends on the quality of porous aggregates. Relevant is a research aimed at reducing density and increasing strength of aggregates, reducing energy intensity of production $[1,7,10-19]$. Porous aggregates with a density of $300-900 \mathrm{~kg} / \mathrm{m}^{3}$ for heatinsulating and structural concrete have been developed $[6,8,9]$. To obtain aggregates, they

\footnotetext{
* Corresponding author: psm58@mail.ru
} 
recommend granular wastes of various industries [9-20], ashes from coal combustion $[13,15,16]$, associated materials of extraction and processing of ores and fuels $[10,14$, 21-23]. The technology of granular foam glass is actively developing [17, 18]. Recent developments have focused on the study of structure formation and hardening of concrete with the participation of a porous aggregate $[15,19,20]$.

A number of promising developments are devoted to highly porous materials from liquid glass [9, 23-26]. Liquid glass is a hydrated alkaline silicate, for example, sodium silicate [9, $24,25]$. On the basis of liquid glass cellular concrete, porous granules for various purposes, piece products can be produced. Porization of liquid glass materials is carried out by swelling $[9,24,25,26]$. The physicochemical features of liquid glass allow one to implement numerous expansion options. To develop effective heat-insulating materials, the choice of composition and optimization of properties of the raw mix based on liquid glass is necessary.

The aim of the work is to study the effect of liquid glass composition on structure and properties of a porous aggregate for lightweight concrete.

\section{Materials and methods of investigation}

The object of the study was the composition of liquid glass and mineral additives. The main mineral component is glass cullet. Other mineral additives contained burn-out or gas-forming components such as gaize, magnetite ore dressing waste and oil shale.

Glass cullet is fragments of sheet glass and glass containers. The chemical composition of glass cullet is, wt. \%: $\mathrm{SiO}_{2} 70-73 ; \mathrm{Al}_{2} \mathrm{O}_{3} 1-3 ; \mathrm{Fe}_{2} \mathrm{O}_{3} 1-3 ; \mathrm{CaO} 5-7 ; \mathrm{MgO} 0-1$; $\mathrm{Na}_{2} \mathrm{O} 3-4, \mathrm{~K}_{2} \mathrm{O} 1-2$.

Gaize consists mainly of silica gel; $\mathrm{SiO}_{2}$ content is $80-85 \%$. Gaize is a part of overburden formed during the development of magnetite ore deposits.

Magnetite ore dressing waste is fine sand containing calcium silicates and aluminosilicates (pyroxenes, garnets, epidote, scapolite, chlorites, feldspars). The waste contains pyrite, calcium carbonate. The chemical composition of the waste is, wt. \%: $\mathrm{SiO}_{2} 39-41 ; \mathrm{Al}_{2} \mathrm{O}_{3} 11-13 ; \mathrm{Fe}_{2} \mathrm{O}_{3} 14-16 ; \mathrm{CaO} 10-12 ; \mathrm{MgO} 5-6 ; \mathrm{SO}_{3} 5-7 ; \mathrm{Na}_{2} \mathrm{O} 2$ -3 ; others $2-4$.

Oil shale is a metamorphic rock comprising from 10 to $30 \%$ of bituminous substances. The chemical composition of oil shale is, wt. \%: Si $17-19 ; \mathrm{Al} 7-10 ; \mathrm{Fe} 10-12$; 17 - 20; S $4-6$; Mg 1 - 3; C $29-32$; H $2-4$.

Sodium liquid glass with a density of $1400 \mathrm{~kg} / \mathrm{m}^{3}$ was used as a blowing agent and connection of components of the molding mass.

Minerals were ground to a specific surface area of $400-450 \mathrm{~m}^{2} / \mathrm{kg}$ and mixed with liquid glass. Granules with a diameter of $10 \mathrm{~mm}$ were formed from the resulting mixture. The granules were dried and fired at a temperature of $700-850{ }^{\circ} \mathrm{C}$. When firing, the granules swell. Thermal transformations in the raw material mass were evaluated by the nature of porous structure and granules' density. The coefficient of expansion was determined as the ratio of granules' size before and after firing. The average pore size is the result of nine measurements in a photograph of chip cleavage. The microstructure of materials was investigated using a JSM-649OLV Energy scanning electron microscope.

\section{Results and discussion}

\subsection{Effect of liquid glass on granules porosity}

Swelling of materials based on liquid glass is due to removal of water, which is a part of sodium hydrosilicates. The amount of water in sodium hydrosilicates depends on the 
temperature of formation of a crystalline phase, silicate module, and alkali concentration. The content of liquid glass significantly affects porous aggregate's structure [9, 24].

Liquid glass is a multifunctional component of the composition studied. At the stage of molding it provides powder mass pinning and formation of granules. During heat treatment it reduces the sintering temperature, provides porosity formation. Compositions with different liquid glass content were studied. Firing was carried out at a temperature of $800{ }^{\circ} \mathrm{C}$ (Table 1). An increase of liquid glass from 40 to $45 \%$ in the composition leads to a decrease in the density of granules by $210 \mathrm{~kg} / \mathrm{m}^{3}$.

Table 1. Liquid glass effect on granules' structure and properties.

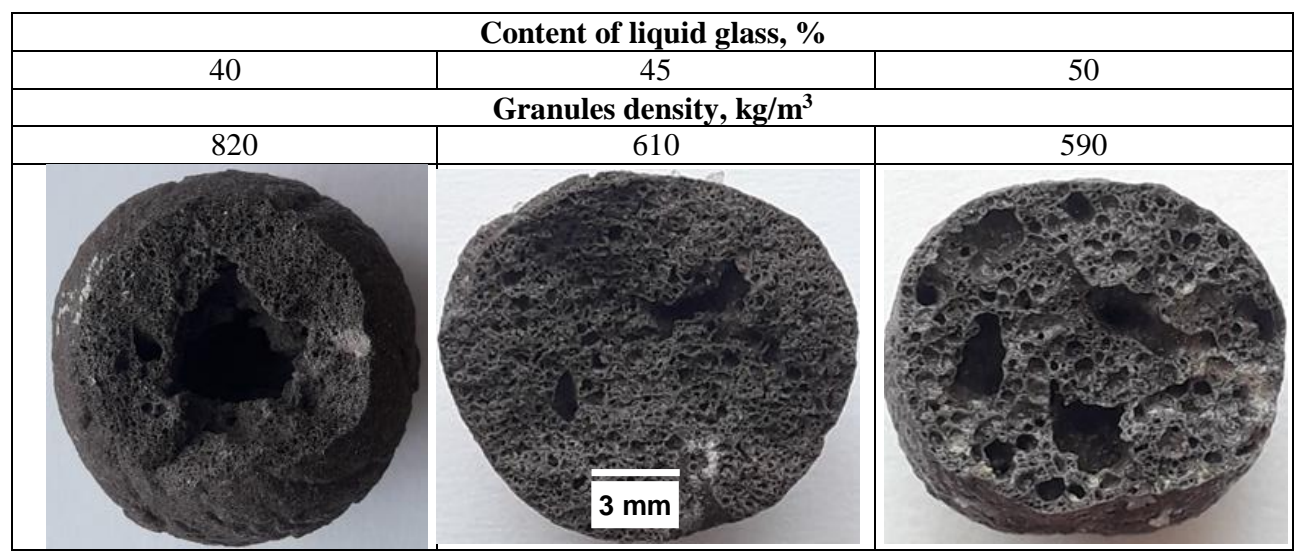

Granules from a composition containing $45 \%$ of liquid glass are characterized by intense expansion and high porosity. The average pore size is from 0.5 to $1.5 \mathrm{~mm}$. Increase in the content of liquid glass is accompanied by a decrease in granules' strength and the formation of large pores.

Therefore, the content of liquid glass in the composition should not exceed $45 \%$.

\subsection{Effect of mineral additives on swelling of granules}

The basic raw material composition contained liquid glass and ground glass break. This composition of the raw mix made it difficult to form granules. Fired material was characterized by uneven porosity, brittleness. To improve properties of a composition and granules, various mineral additives effect was investigated. Introduction of mineral additives has improved molding properties of the composition. The flocking rock provides high plasticity of the composition and strength of granules before firing.

To clarify the content of mineral additives, the structure of fired granules was investigated (Figure 1). The pore-forming ability of magnetite ore dressing wastes is due to dehydration of aluminosilicates, decomposition of pyrite, calcite. Oil shale contains organic matter; during its combustion a gas phase is formed. Flask rock provides formation of pores in the granules due to evaporation of water, released during dehydration of minerals.

Influence of mineral additive type is observed at a concentration of $20 \%$, along with that the largest swelling of granules is provided by magnetite ore dressing waste. For compositions containing $25 \%$ of mineral additives, a high coefficient of expansion is achieved when using gaize. At high concentrations of magnetite ore dressing waste the melting point decreases and the gas-holding ability of the composition decreases. As a result, the number of pores in the granules decreases, while the size of the cells increases. When firing a composition containing oil shale, part of the organic matter burns out until the mass softens, therefore, the coefficient of expansion of granules is small. 


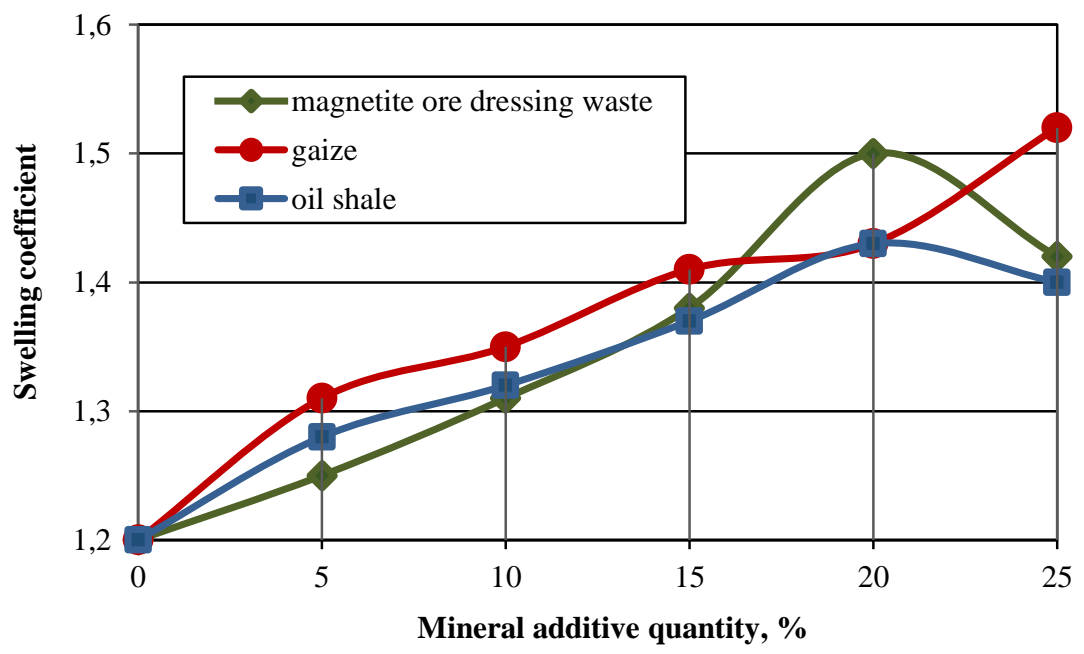

Fig. 1. Mineral additives effect on granules swelling.

The type of mineral additives affects the nature of porosity (Table 2). Comparison of granules structure obtained from mixtures with the optimal content of mineral additives showed that the most uniform distribution of pores is achieved when using gaize. In this case, the highest porosity is formed using wastes from enrichment of magnetite ores.

Table 2. Effect of mineral additives on granules' structure.

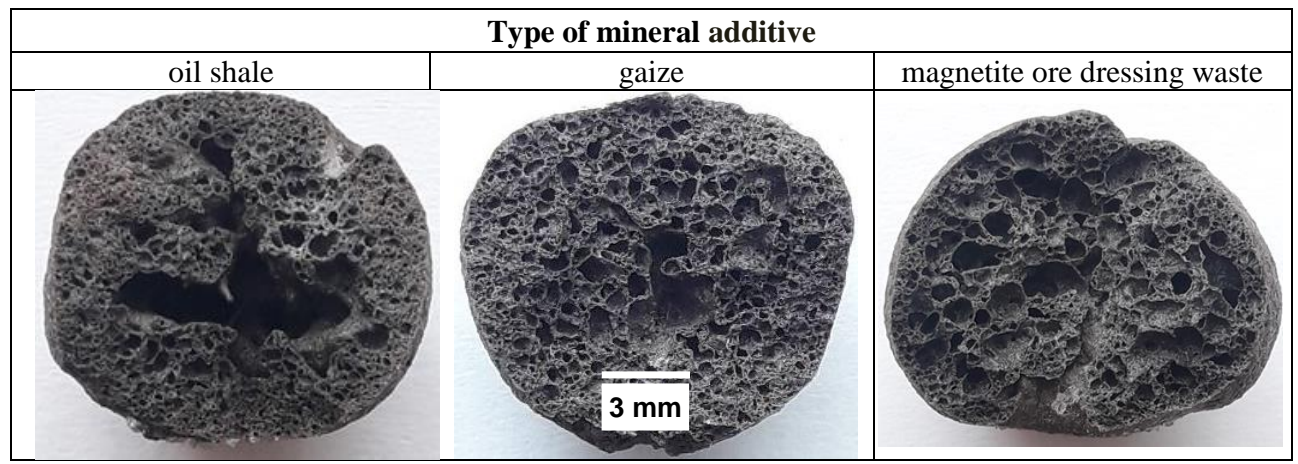

This served as a prerequisite for combination of various mineral additives in the composition. It is established that combining gaize and magnetite ores enrichment waste, the best conditions for granules' formation are provided. Expanded granules have a high and uniform porosity. When combining gaize and oil shale, the coefficient of expansion increases with a lower content of mineral additives.

Therefore, to improve technological properties of the composition and increase the porosity of granules, a multicomponent feed mixture is preferred.

\subsection{Influence of preparation method of the composition on granules' properties}

The multicomponent mixture studied was characterized by slow hardening of the granules before firing, which complicated the technology of producing an aggregate for lightweight concrete. Introduction of sodium salts accelerated raw material mass hardening. Effect of 
sodium additives on the formation of granule porosity was studied. Optimal concentration of sodium additives in the composition of $5-7 \%$ provides increased porosity, low density, minimizes defects in granules.

The multicomponent composition requires more thorough preparation of a mixture and smoothness improvement. Influence of preparation method of the composition was studied (Table 3).

Table 3. Methods of raw materials mixing.

\begin{tabular}{|c|l|}
\hline Method & \multicolumn{1}{|c|}{ Raw material mixing procedure } \\
\hline 1 & liquid glass + (raw mix + sodium additive) \\
\hline 2 & $\begin{array}{l}\text { liquid glass + activated mass (raw mix + sodium } \\
\text { additive) }\end{array}$ \\
\hline 3 & $\begin{array}{l}\text { activated mass (raw mix + sodium additive) + liquid } \\
\text { glass }\end{array}$ \\
\hline
\end{tabular}

Along with the usual mixing of the raw mixture, activation of solid components of the composition by additional grinding in a high-speed ball mill was used. Activation contributed to equal distribution of components, increasing composition's reactivity due to mechanical stress and chemical effect of sodium additive on the particle surface. The specific surface area of the activated raw material mixture is $500-520 \mathrm{~m}^{2} / \mathrm{kg}$.

Method 1 involved the introduction of liquid glass into a mixture of dry components. The resulting mass was characterized by unequal distribution of additives.

Method 2 consisted of adding liquid glass to the activated mixture. The sharp loss in plasticity of the mass complicated the mixing of the mixture. The mass was characterized by heterogeneity and viscosity.

Method 3 is based on gradual introduction of the activated mixture into fluid glass. The method allowed to distribute the components equally, increase the plasticity of a mixture, accelerate granules formation. This method is recognized as preferred.

The formation of the porous structure of the granules is based on pyroplastic expansion. The thermal exposure mode allows you to adjust the process of porosity.

The effect of firing temperature on the porous structure of the granules was investigated (Figure 2, Table 4).

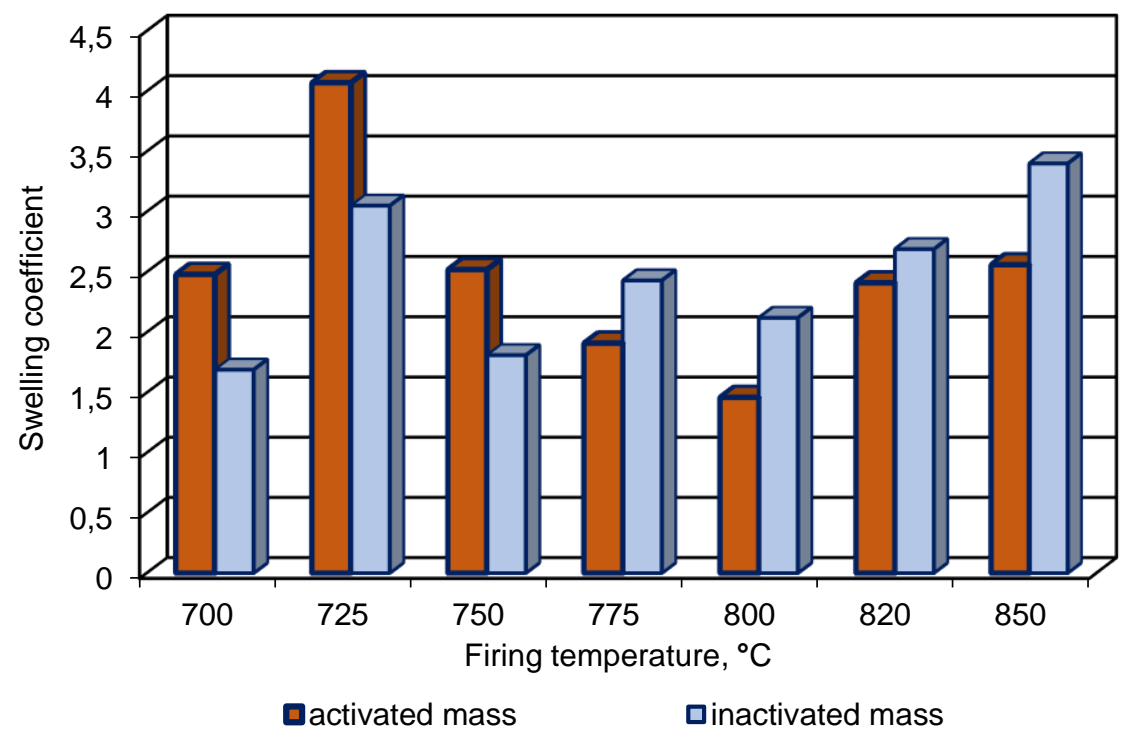


Fig. 2. Effect of temperature on the expansion of granules from mixtures by various preparations.

Table 4. Effect of firing temperature on the structure and properties of granules.

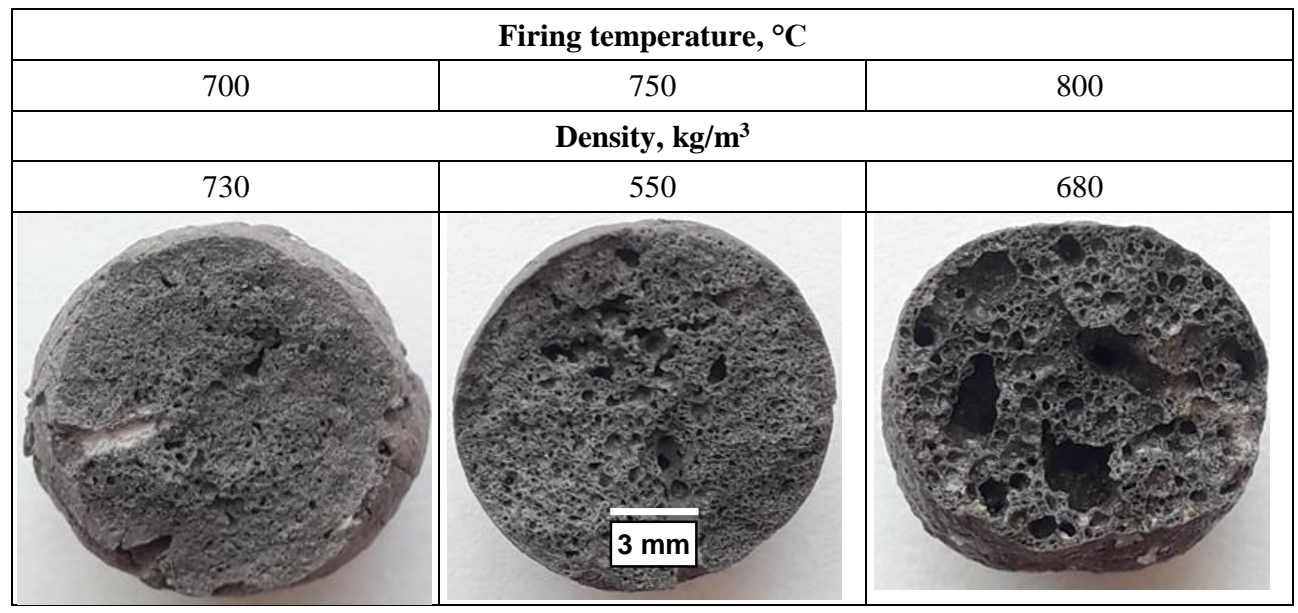

Intensive bloating of granules occurs in the temperature range of $700-725{ }^{\circ} \mathrm{C}$ (Figure 2). The granules fired at a temperature of $725^{\circ} \mathrm{C}$ have a high porosity; the average cell size was $1.0-1.5 \mathrm{~mm}$ (Table 4). Firing of granules at higher temperatures is accompanied by melting of granules, a decrease in expansion coefficient of the composition. This is due to the loss of gas-holding ability of the granules due to a decrease in the viscosity of the silicate mass.

Therefore, mechanical and chemical activation of the composition provides low-temperature swelling of the granules.

\subsection{Properties of porous aggregate and lightweight concrete}

The properties of granules synthesized by the developed technology are investigated. Compared with expanded clay gravel, a new porous aggregate obtained from industrial raw materials at a low firing temperature, has improved thermal characteristics (Table 5).

Table 5. Comparative characteristics of porous granules.

\begin{tabular}{|l|c|c|}
\hline \multirow{2}{*}{ Characteristics } & \multicolumn{2}{c|}{ Types of filling aggregates } \\
\cline { 2 - 3 } & $\begin{array}{c}\text { lightweight } \\
\text { aggregate concrete }\end{array}$ & $\begin{array}{c}\text { synthesized } \\
\text { granules }\end{array}$ \\
\hline Firing temperature, ${ }^{\circ} \mathrm{C}$ & $900-1200$ & 725 \\
\hline Density of a granule, $\mathrm{kg} / \mathrm{m}^{3}$ & 790 & 490 \\
\hline Bulk density, $\mathrm{kg} / \mathrm{m}^{3}$ & $450-500$ & $250-300$ \\
\hline Heat conductivity coefficient, $\mathrm{W} /\left(\mathrm{m}^{\circ}{ }^{\circ} \mathrm{C}\right)$ & 0.09 & 0.06 \\
\hline
\end{tabular}

In cement concretes, there is a danger of alkali-silicate aggregate reactions obtained on the basis of amorphous silica [19, 20,24]. Influence of various environments on stability of the synthesized aggregate is investigated. The granules were kept in water, in solutions of magnesium chloride, sodium hydroxide and calcium. After 30 days, the granules showed chemical resistance and preserved their structure.

It was revealed that the composition of the raw mixture affects the ability of granules to 
absorb liquids (Figure 3). This is due to the type of pores in the structure of the granules.

Mixture 1, including oil shale and silica clay rock, provided obtaining of granules having a large number of open large pores. Granules from mixture 1 are characterized by the highest absorption of liquids.

Mixture 2, containing magnetite ore dressing waste and silica clay rock, was used to produce granules in which the number of open pores was reduced.

Mixture 3, combining magnetite ore dressing waste, silica clay rock and sodium additive, ensured the formation of granules with a compacted shell. This contributed to a decrease in absorption of granules by liquids.

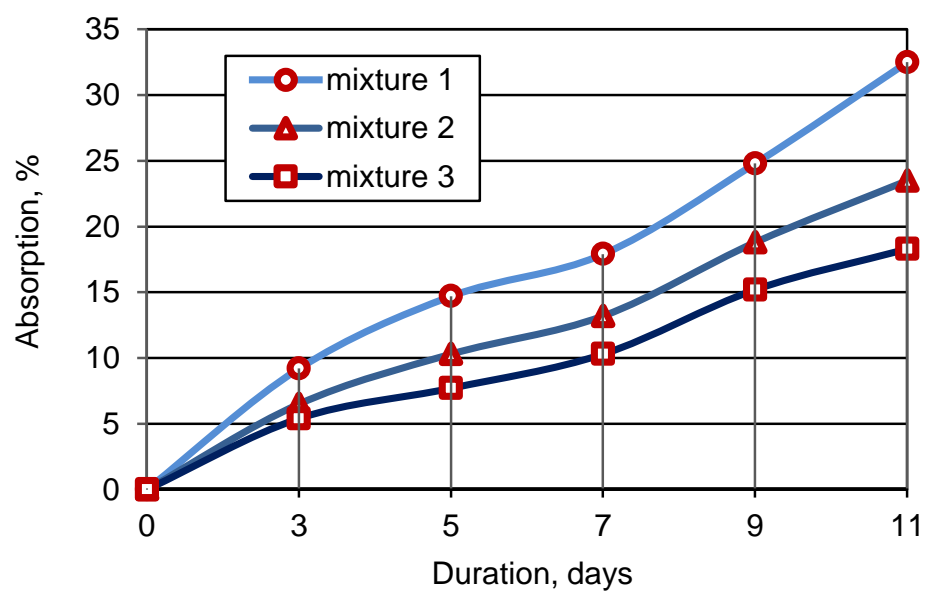

Fig. 3. Influence of raw mixtures' composition on granules' ability to absorb liquid.

Changing the absorption capacity allows expanding the scope of use of porous granules: lightweight concrete aggregate, sound-absorbing materials, heat-insulating backfill.

Concrete mixtures based on the aggregate developed and mineral binders are investigated. It was revealed that caustic magnesium carbonate and liquid glass provide reliable adhesion of the granules of the porous aggregate.

The preference of water glass as an adhesive for lightweight concrete is due to its high adhesive ability and the ability to control the mass' state. The binders based on liquid glass and siliceous filler are investigated. It has been revealed that the use of flocking rock as filler provides necessary consistency of the concrete mixture and high adhesion of the aggregate binder to the granules.

It was determined that under the following ratio of «porous aggregate: liquid-glass binder $-1: 2.0$ and $1: 2.5 »$, the contact homologation of granules is achieved (Figure 4). The lightweight concrete obtained has a density of $350-400 \mathrm{~kg} / \mathrm{m}^{3}$.
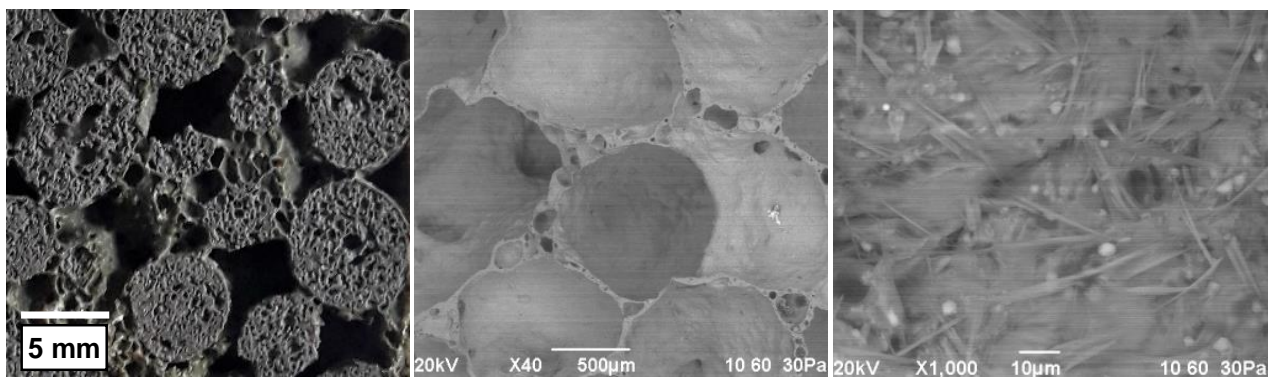

Fig. 4. Concrete structure based on porous aggregate. 
The heat treatment mode for accelerated hardening of lightweight concrete based on water glass has been established. At a temperature of $100{ }^{\circ} \mathrm{C}, 4.5-5.0 \mathrm{MPa}$ strength is achieved. An increase in temperature up to 125 and $150{ }^{\circ} \mathrm{C}$ leads to the swelling of a binder located between the grains of concrete aggregate. Therefore, control of heat treatment temperature allows you to obtain concrete of different structures.

\section{Conclusion}

A resource-saving technology for producing of porous granules with a density of $250-300 \mathrm{~kg} / \mathrm{m}^{3}$ has been developed. It has been established that the use of a multicomponent composition based on liquid glass provides a highly porous granule structure due to a combination of various pore formation mechanisms.

Mechanical and chemical activation of a raw mixture improves technological properties of the molding mixture and provides low-temperature swelling of the granules. Possibility of regulating the porosity of granules through a combination of various mineral additives of technogenic origin was revealed.

Porous granules are used as aggregate for lightweight concrete. A formulation of the concrete mixture containing a binder based on liquid glass is proposed. The mode of accelerated hardening of light concrete is recommended. The integrated use of water glass to obtain granular aggregate and concrete mixtures ensures technological scheme's compactness.

\section{References}

1. D. Sarwono, D. Rochim, A. Setyawan, Procedia Eng. 171, 1429 (2017)

2. Y. Wang, C. Ma, Y. Liu, D. Wang, J. Liu, Int. J. Heat Mass Transf. 125, 387 (2018)

3. J. Xie, J. Liu, F. Liu, J. Wang, P. Huang, J. Clean. Prod. 235, 1240 (2019)

4. T.J. Chandni, K.B. Anand, J. Build. Eng. 19, 154 (2018)

5. R. Vinai, M. Soutsos, Cem. Concr. Res. 116, 45 (2019)

6. T.V. Lam, D.T. Vu, V.K. Dien, B.I. Bulgakov, E.A. Korol, Magaz. Civil Eng. 84, 173 (2018)

7. O. Miryuk, IOP Conf. Ser.: Mater. Sci. Eng. 365, 032052 (2018)

8. Y. Zaetang, A. Wongsa, V. Sata, P. Chindaprasirt, Constr. Build. Mater. 48, 585 (2013)

9. O. Miryuk, E3S Web Conf. 97, 02025 (2019)

10. J.N. Farahani, P. Shafigh, H.B. Mahmud, Procedia Eng. 184, 778 (2017)

11. H. Tamai, H.Tamai, Procedia Eng. 125, 732 (2015)

12. V. Vaganov, M. Popov, A. Korjakins, G. Šahmenko, Procedia Eng. 172, 1204 (2017)

13. V. Cerny, M. Kocianova, R. Drochytka, Procedia Eng. 195, 9 (2017)

14. Y. Sun, P. Gao, F. Geng, H. Li, L. Zhang, H. Liu, Mater. Lett. 209, 349 (2017)

15. E. Tkach, A. Rakhimov, IOP Conf. Ser.: Mater. Sci. Eng. 365, 032014 (2018)

16. K. Skoczylas, T.Rucińska, Cement Wapno Beton 3, 206 (2018)

17. S. Yang, T.-C. Ling, H. Cui, C.S. Poon, Constr. Build. Mater. 209, 522 (2019)

18. J.T. Kevern, Q.C. Nowasell, Constr. Build. Mater. 161, 229 (2018)

19. H. Tamai, H.Tamai, Procedia Eng. 125, 732 (2015)

20. G. Pia, U. Sanna, Constr. Build. Mater. 44, 551 (2013)

21. L. Hou, J. Li, Zh. Lu, Yu. Niu, T. Li, Constr. Build. Mater. 227, 116698 (2019)

22. Q. Gao, X. Song, X. Bu, J. He, Constr. Build. Mater. 226, 280 (2019)

23. A.M. Rashad, Constr. Build. Mater. 93, 1236 (2015)

24. S.A. Mizuryaev, A.G. Chiknovorian, G.S. Solopova, R.V. Demidov, Procedia Eng. 153, 599 (2016) 
25. S.A. Mizuriaev, A.Yu. Zhigulina, G.S. Solopova, Procedia Eng. 111, 540 (2015)

26. Y. Liu, C. Shi, Z. Zhang, N. Li, Resour., Conser. Recyc. 144, 297 (2019) 